\title{
Prioritas Pengembangan Infrastruktur Pada Wisata Pantai Teluk Hijau Desa Sarongan, Kabupaten Banyuwangi
}

\author{
Arwi Yudhi Koswara dan Yonathan Gustaf \\ Perencanaan Wilayah dan Kota, Fakultas Arsitektur Desain dan Perencanaan dan Kebumian \\ Institut Teknologi Sepuluh Nopember \\ e-mail: arwiyudhi@gmail.com
}

\begin{abstract}
Abstrak-Suatu kawasan wisata perlu memperhatikan kenyamanan pengunjung. Hal itu dapat terpenuhi apabila terdapat perilaku masyarakat yang ramah wisata dilokasi Daya Tarik Wisata dan didukung dengan keberadaan infrastruktur yang lengkap. Salah satu daya tarik wisata pantai unggulan di Banyuwangi yang ada di Teluk Hijau belum mempunyai infrastruktur yang memadai, seperti: jaringan jalan, jaringan listrik, dan penerangan jalan. Meski demikian, pengunjung wisata pantai Teluk Hijau tetap justru meningkat setiap tahunnya. Pantai di Teluk hijau merupakan kawasan konservasi. Oleh karena itu, penelitian ini bertujuan untuk menganalisis green infrastruktur yang dibutuhkan wisata pantai Teluk Hijau, Kabupaten Banyuwangi. Untuk mengetahui hal tersebut, penelitian ini terbagi menjadi beberapa tahap, yaitu menilai tingkat kinerja infrastruktur eksisting dan tingkat kepentingan infrastruktur pariwisata di wisata Pantai Teluk Hijau secara deskriptif, serta mengidentifikasi infrastruktur prioritas berdasarkan analisis tingkat kinerja dan kepentingan dengan metode IPA (importance-performance analysis). Output dari penelitian ini adalah teridentifikasinya green infrastruktur prioritas di wisata pantai Teluk Hijau, yaitu penyediaan titik evakuasi, penyediaan jaringan jalan, penyediaan pos kesehatan, penyediaan toilet, terminal angkutan, moda transportasi, jaringan telekomunikasi.
\end{abstract}

Kata Kunci- Daya Tarik Wisata, Green Infrastruktur Prioritas, Wisata Pantai.

\section{PENDAHULUAN}

$\mathrm{P}$ ARIWISATA adalah aktivitas mencari kesenangan dengan menikmati berbagai hiburan untuk melepaskan lelah [1]. Pariwisata adalah segala sesuatu yang berhubungan dengan wisata, termasuk pengusahaan objek dan daya tarik wisata serta usaha-usaha yang terkait dibidang tersebut [2]. Pariwisata sebagai bentuk industri baru di dunia yang memiliki pengaruh besar terhadap perekonomian suatu kabupaten atau wilayah, sehingga sektor pariwisata perlu dikembangkan untuk meningkatkan perekonomian [3].

Kunci utama untuk menciptakan sebuah daerah dengan industri pariwisata yang baik adalah terwujudnya kenyamanan pengunjung. Kenyamanan pengunjung akan terpenuhi apabila terdapat perilaku masyarakat yang ramah pariwisata dan terdapat infrastruktur yang mendukung pelayanan wisata [4]. Infrastruktur merupakan dasar dari keberadaan suatu lokasi wisata dan faktor penting dalam menjaga keberlangsungan dan pertumbuhan suatu lokasi wisata. [5]

Kabupaten Banyuwangi merupakan salah satu wilayah yang memiliki keberagaman wisata, khususnya pada sektor pantai
[6]. Salah satu potensi sumber daya alam pada sektor pantai di Kabupaten Banyuwangi adalah wisata pantai yang berlokasi di Teluk Hijau. Pantai teluk hijau termasuk dalam wilayah pengembangan pariwisata III (WPP III). [7]. Kawasan ini merupakan taman nasional meru betiri yang dilindungi.

Pengunjung wisata pantai Teluk Hijau selalu mengalami peningkatan setiap tahunnya [8]. Pada tahun 2014 tercatat bahwa pengunjung pantai Teluk Hijau berjumlah 49.805 jiwa. Sementara itu, pada tahun 2015 pengunjung pantai Teluk Hijau mengalami peningkatan menjadi 70.842 jiwa [9]. Peningkatan dari kunjungan wisatawan menuju Teluk Hijau semakin signifikan. Hal ini dibuktikan oleh data pengunjung pada tahun 2016 yang melonjak sebesar 100\% dengan ratarata jumlah pengunjung sebesar 1.000 jiwa per hari [10].

Kondisi eksisting infrastruktur yang termasuk dalam kategori kurang baik adalah jaringan jalan, jaringan listrik, dan penerangan jalan [11]. Wisata pantai Teluk Hijau belum mempunyai aksesibilitas yang memudahkan wisatawan untuk menuju ke lokasi wisata tersebut [12]. Akses darat yang harus ditempuh untuk menuju wisata pantai Teluk Hijau sejauh 90 $\mathrm{km}$ ke arah barat daya dari Kabupaten Banyuwangi yang terletak di Kecamatan Pesanggaran. Waktu tempuh yang harus dilalui oleh wisatawan yaitu \pm 2 jam dari Kabupaten Banyuwangi [12]. Jaringan jalan menuju lokasi Pantai Teluk Hijau masih berupa jalan makadam, sehingga perlu perhatian khusus pada akses jalan menuju pantai. Kondisi jalan menuju pantai teluk hijau menunjukan bahwa sektor infrastruktur dari segi aksesibilitas belum memenuhi standar yang sudah di tetapkan pada PP No.50 Tahun 2011 Tentang Rencana Induk Pembangunan Kepariwisataan Nasional Pasal 17 yang dimaksudkan untuk memudahkan wisatawan dalam pergerakan menuju tempat wisata Pantai Teluk Hijau [13].

Untuk mengatasi masalah minimnya penyediaan infrastruktur di lokasi wisata Pantai Teluk Hijau, Dinas Budaya dan Pariwasata Kabupaten Banyuwangi telah mencanangkan program peningkatan sarana dan prasarana di kawasan Pantai Teluk Hijau yang masuk wilayah pengembangan pariwisata III Kabupaten Banyuwangi. Program tersebut mengagendakan pembangunan sarana dan prasana pada wilayah Pantai Teluk Hijau sebagai prioritas pembangunan daerah. Sejalan dengan kondisi wisata Pantai Teluk Hijau yang belum memenuhi standar penyediaan infrastruktur pariwisata di daerah konservasi, maka perlu adanya analisa mengenai penyediaan green infrastruktur prioritas pada wisata Pantai Teluk Hijau di Kabupaten Banyuwangi. [14] 


\section{METODE PENELITIAN}

\section{A. Jenis dan Pendekatan Penelitian}

Pendekatan yang digunakan dalam penelitian ini adalah pendekatan rasionalistik dengan berlandaskan fakta empiri sebagai tombak kebenaran penelitian. Sementara itu, jenis penelitian dalam penelitian ini adalah kuantitatif.

\section{B. Variabel Penelitian}

Variabel penelitian yang digunakan untuk mengidentifikasi infrastruktur prioritas sejumlah variabel yaitu atraksi alam, atraksi buatan, moda transportasi, penanda, jalur drainase, tempat makan, jaringan telekomunikasi, pos keamanan, terminal angkutan, gazebo, jaringan listrik, tempat sampah, pos kesehatan dan penginapan.

\section{Populasi dan Sampel}

Populasi pada penelitian ini adalah seluruh responden yang berpengaruh dalam pengembangan green infrastruktur Wisata Pantai Teluk Hijau. Sementara itu, sampel penelitian diperoleh melalui teknik purposive sampling dengan tujuan agar responden yang terpilih merupakan seseorang yang memahami kondisi infrastruktur dan kedudukan lokasi wisata di Kabupaten Banyuwangi. Adapun sampel penelitian ini dapat digolongkan menjadi 3 jenis berdasarkan latar belakang pekerjaan yaitu, governance, public sector, dan akademisi.

Tabel 1.

Sampel Penelitian

\begin{tabular}{cl}
\hline \hline Penggolongan Responden & \multicolumn{1}{c}{ Responden Penelitian } \\
\hline & Dinas Kebudayaan dan Pariwisata \\
Governance & BAPPEDA \\
& Desa Sarongan \\
\hline Public Sector & Kelompok sadar wisata \\
\hline Akademisi & Akademisi Kabupaten Banyuwangi \\
\hline
\end{tabular}

\section{Teknik Analisis}

Tahap awal pada penelitian ini yaitu proses identifikasi tingkat kinerja infrastruktur eksisting dan tingkat kepentingan infrastruktur di wisata pantai Teluk Hijau menggunakan analisis kuantitatif dengan scoring skala likert. Tahap ini dilakukan untuk melihat ketersediaan green infrastruktur dan kondisi infrastruktur di wilayah wisata pantai Teluk Hijau. Selanjutnya, dilakukan analisis IPA (importance-performance analysis) untuk menghasilkan green infrastruktur prioritas pariwisata di daerah wisata Pantai Teluk Hijau.

\section{HASIL DAN PEMBAHASAN}

\section{A. Ruang Lingkup Wilayah Studi}

Penelitian ini berlokasi di Desa Sarongan, Kecamatan Pesanggaran Kabupaten Banyuwangi, Jawa Timur. Desa Sarongan mempunyai luas sebesar $47,04 \mathrm{~km}^{2}$ dengan batas administrasi sebagai berikut:

- Sebelah Utara : Desa Kalibaru

- Sebelah Barat : Kabupaten Jember

- Sebelah Selatan : Samudera Hindia

- Sebelah Timur : Desa Kandangan

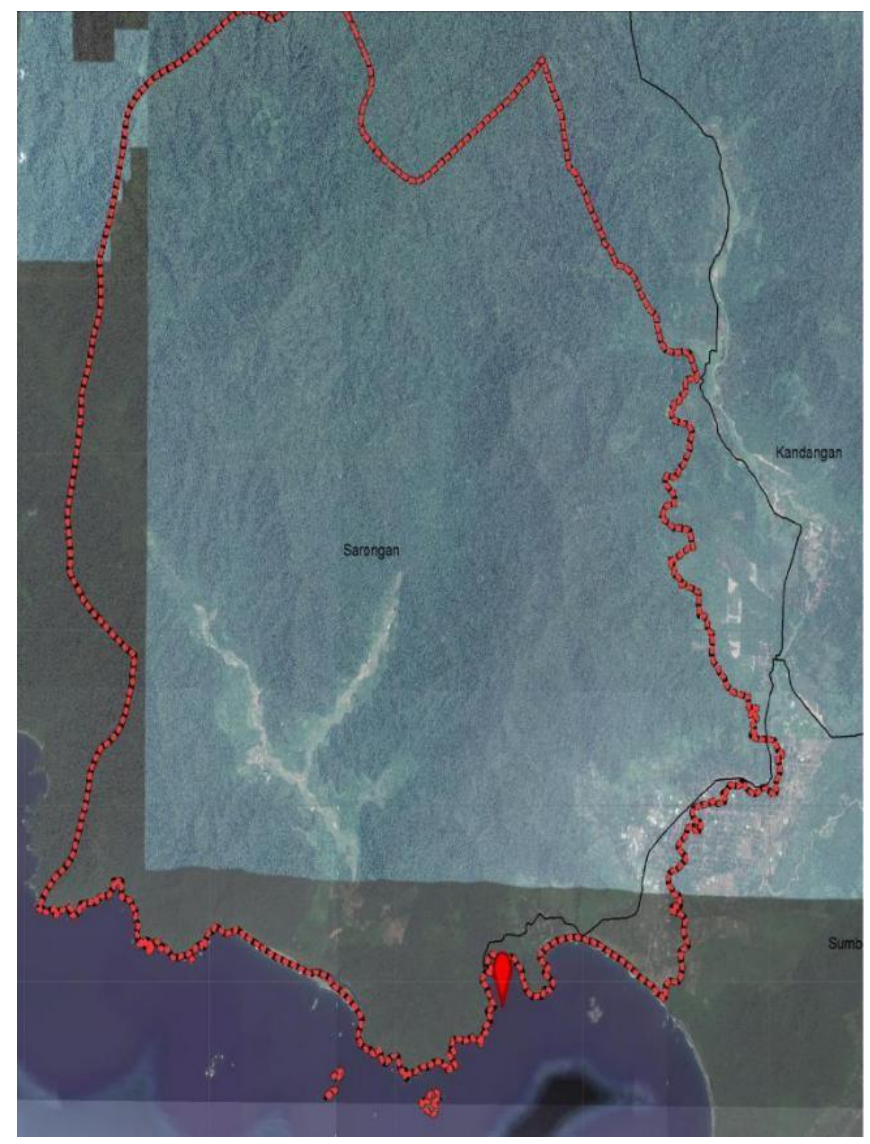

Gambar 1. Peta Batas Wilayah Studi

\section{B. Karakteristik Wilayah Studi}

Kawasan wisata pantai Teluk Hijau termasuk dalam kawasan Taman Nasional Merubetiri. Hal ini mengindikasikan bahwa kawasan wisata pantai teluk hijau berada pada zona yang dilindungi dalam segi pelestarian alam. Hal ini menjadi pertimbangan peneliti dalam menyediakan jenis infrastruktur yang bersifat green infrasstruktur, maksudnya infrastruktur yang ramah lingkungan, sedikit menghasilkan sampah, dan lebih sedikit membutuhkan energi. Meskipun kawasan wisata pantai Teluk Hijau termasuk dalam zona yang dilindungi tetapi wisata ini termasuk kedalam wilayah prioritas pariwisata tingkat III (WPP III). Pada wilayah studi sudah dicanangkan bahwa prioritas pembangunan sarana dan prasrana termasuk ke dalam wisata pantai Teluk Hijau.

\section{Kondisi Eksisting Infrastruktur Pada Wisata Pantai} Teluk Hijau

Pada kawasan wisata pantai Teluk Hijau mempunyai beberapa infrastruktur yang sudah terbangun. Infrastruktur pada kawasan wisata pantai Teluk Hijau tidak hanya didalam kawasan pantai tetapi juga diluar kawasan wisata pantai.

Setelah melakukan survey primer maka didapatkan 8 infrastruktur terbangun yaitu ;

1. Penyediaan jaringan jalan

2. Penandaan/ petunjuk arah

3. Penyediaan kantor pusat informasi

4. Penyediaan lahan parkir terpusat 
5. Penyediaan kantor pos keamanan

6. Wisata kuliner terpusat

7. Gazebo dan tempat duduk individu/ keluarga

Berikut beberapa visualisasi infrastruktur terbangun pada kawasan wisata pantai Teluk Hijau.

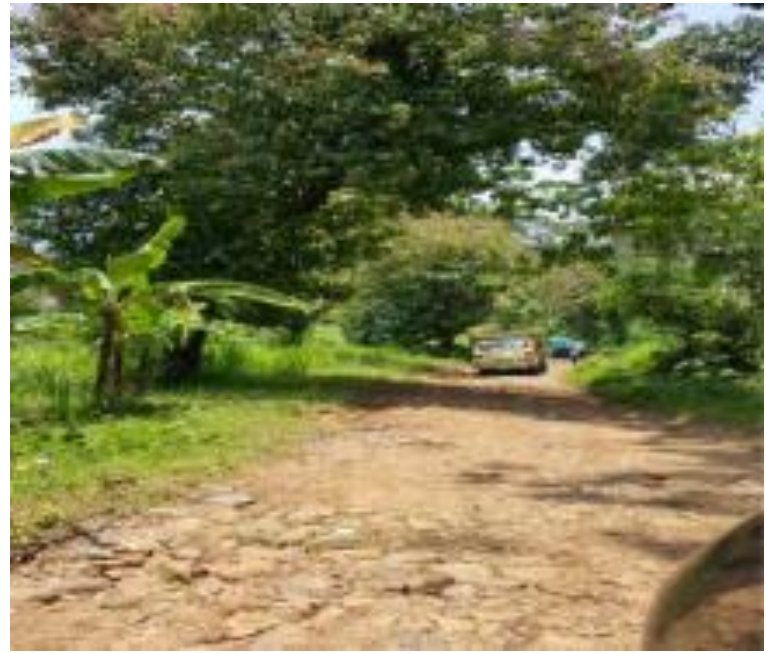

Gambar 2. Penyediaan Jaringan Jalan

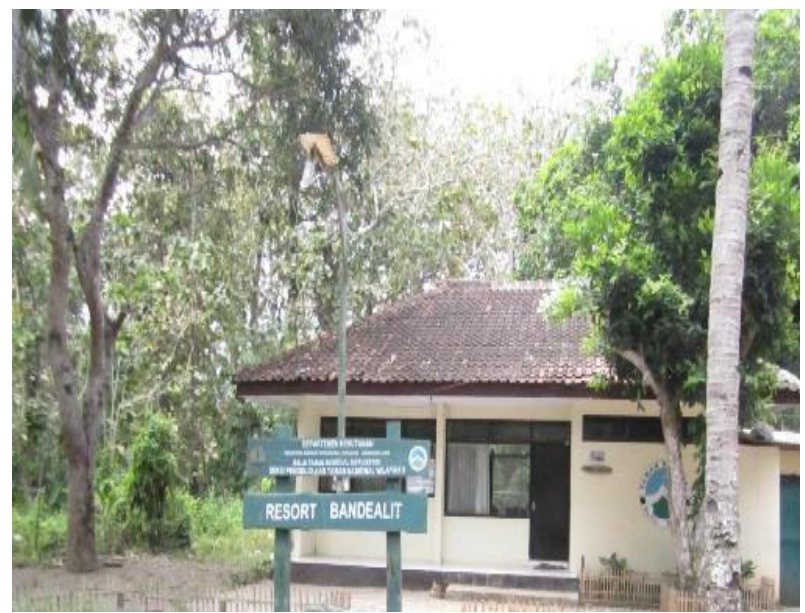

Gambar 3. Kantor Pos Keamanan

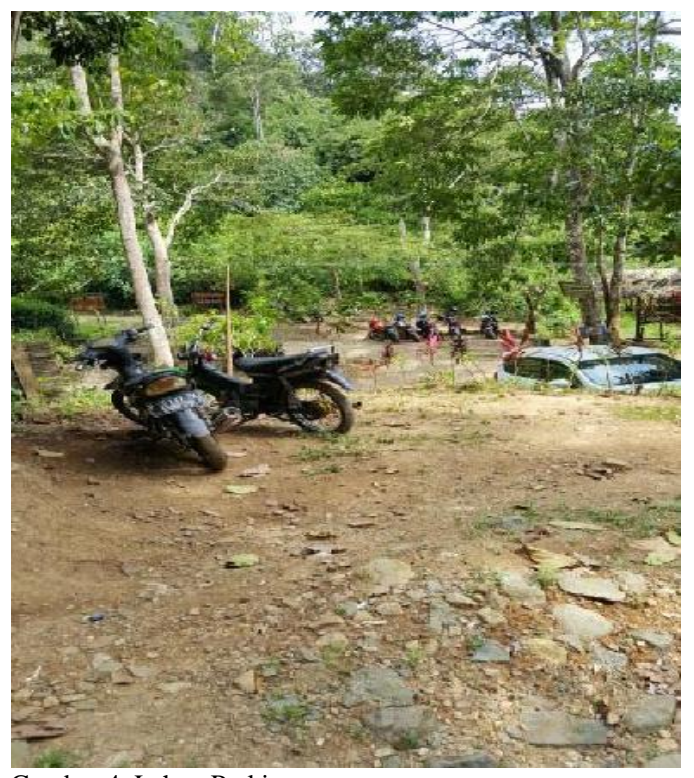

Gambar 4. Lahan Parkir

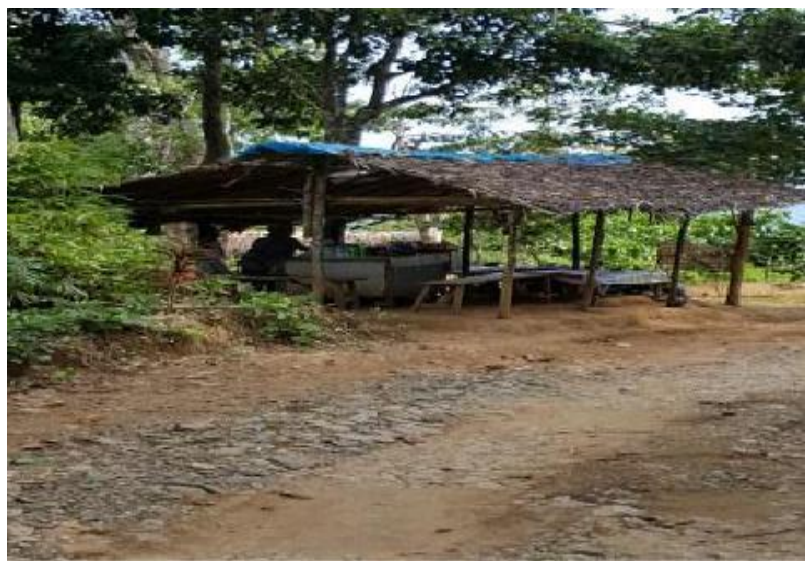

Gambar 5. Gazebo

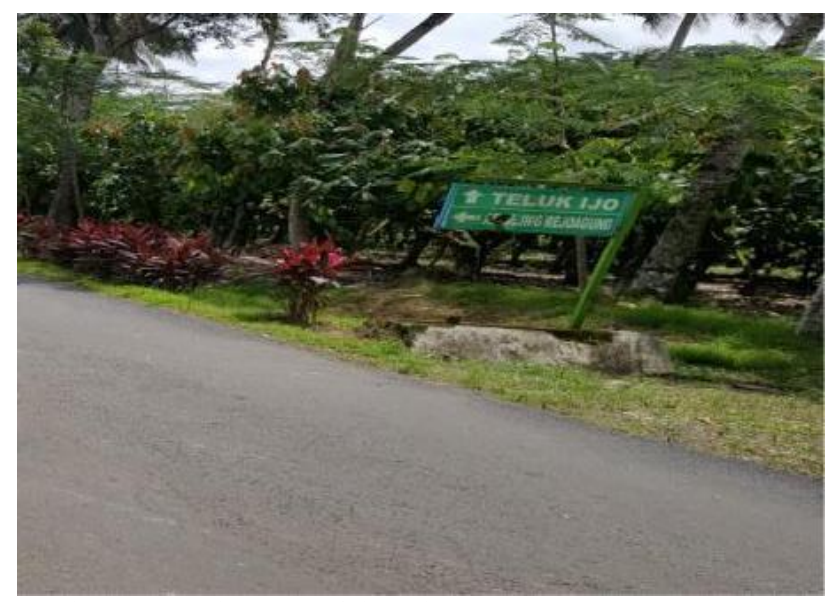

Gambar 6. Penandaan/ Petunjuk Arah

\section{Tingkat Kinerja Infrastruktur Pada Wisata Pantai Teluk} Hijau

Tingkat kinerja yang diperoleh merupakan hasil persepsi responden terhadap kinerja masing-masing infrastruktur yang sudah ada. Penilaian menggunakan skala likert dengan rentang nilai $1 \mathrm{~s} / \mathrm{d} 4$ (sangat buruk-buruk-baik-sangat baik).

Berikut merupakan tabel tingkat kinerja green infrastruktur di wisata Pantai Teluk Hijau, Kabupaten Banyuwangi.

Tabel 2

Tingkat Kinerja Infrastruktur di Wisata Pantai Teluk Hijau

\begin{tabular}{lc}
\hline \hline \multicolumn{1}{c}{ Jenis Infrastruktur } & Rata-Rata Nilai \\
\hline Penyediaan Jaringan Jalan & 1.5 \\
Moda Transportasi & 1.5 \\
Penandaan atau Penunjuk Arah & $3.83^{*}$ \\
Terminal Angkutan & 1.5 \\
Jaringan Listrik & 1 \\
Jaringan Air Bersih & 1.6 \\
Jaringan Telekomunikasi & 1 \\
Penyediaan Sampah Terpusat & 2.66 \\
TIC (tourism information centre) & 3.66 \\
Penyediaan Lahan Parkir Terpusat & 2.16 \\
Penyediaan kantor / pos keamanan & 3.33 \\
Penyediaan pos kesehatan & 1.33 \\
Penyediaan titik evakuasi & 1.33 \\
Penyediaan Toilet & 1 \\
Wisata Kuliner & 1 \\
Penyediaan fasilitas penginapan & 2 \\
Pusat oleh - oleh & 1 \\
Gazebo (shelter) & 3.16 \\
Tempat duduk keluarga / individu & 1.16 \\
\hline Nilai Rata-Rata $\quad$ Kinerja & 1.87 \\
Infrastruktur Eksisting &
\end{tabular}


Adapun infrastruktur dengan tingkat kinerja tertinggi adalah penandaan (penunjuk arah), sementara infrastruktur dengan tingkat kinerja terendah meliputi jaringan listrik, jaringan telekomunikasi, penyediaan toilet, wisata kuliner, dan pusat oleh-oleh.

\section{E. Tingkat Kepentingan Infrastruktur Pada Wisata Pantai Teluk Hijau}

Tingkat kepentingan merupakan penggabungan nilai ratarata dari persepsi responden terhadap penting/tidaknya keberadaan suatu infrastruktur pada wisata pantai Teluk Hijau. Dengan metode scoring menggunakan skala likert, bobot penilaian terhadap tingkat kepentingan infrastruktur diberi rentang $1 \mathrm{~s} / \mathrm{d} 4$ (sangat tidak penting-tidak penting -penting sangat penting). Berikut merupakan tabel tingkat kepentingan green infrastruktur di wisata Pantai Teluk Hijau, Kabupaten Banyuwangi.

Tabel 3.

Tingkat Kepentingan Infrastruktur di Wisata Pantai Teluk Hijau

\begin{tabular}{lc}
\hline \hline \multicolumn{1}{c}{ Jenis Infrastruktur } & Rata-Rata Nilai \\
\hline Penyediaan Jaringan Jalan & 3.8 \\
Moda Transportasi & 3.5 \\
Penandaan atau Penunjuk Arah & 3.83 \\
Terminal Angkutan & 3.16 \\
Jaringan Listrik & 3.3 \\
Jaringan Air Bersih & 3.5 \\
Jaringan Telekomunikasi & 3.8 \\
Penyediaan Sampah Terpusat & 4 \\
TIC (tourism information centre) & 3.8 \\
Penyediaan Lahan Parkir Terpusat & 3.8 \\
Penyediaan kantor / pos keamanan & 3.3 \\
Penyediaan pos kesehatan & 3.8 \\
Penyediaan titik evakuasi & 4 \\
Penyediaan Toilet & 3.66 \\
Wisata Kuliner & 2.83 \\
Penyediaan fasilitas penginapan & 2 \\
Pusat oleh - oleh & 2.66 \\
Gazebo (shelter) & 3.16 \\
Tempat duduk keluarga / individu & 1.66 \\
\hline Nilai Rata-Rata Kepentingan & 3.35 \\
\hline
\end{tabular}

Berdasarkan tabel tersebut, diketahui bahwa terdapat dua jenis infrastruktur yang memiliki tingkat kepentingan tinggi, yaitu penyediaan titik evakuasi dan tempat sampah. Sementara itu, infrastruktur dengan kepentingan rendah adalah tempat duduk keluarga (individu).

\section{F. Insfrastruktur Prioritas Pada Wisata Pantai Teluk Hijau}

Untuk mengetahui infrastruktur prioritas pada wisata pantai Teluk Hijau dilakukan analisis IPA (Importance Performance Analysis) menggunakan software SPSS. Analisis ini bertujuan untuk mencari nilai kesenjangan antara tingkat kinerja infrastruktur eksisting dengan tingkat kepentingan, serta membagi masing-masing infrastruktur ke dalam 4 kuadran prioritas.

Kuadran I : Infrastruktur yang harus ada dan butuh dikembangkan (focus effort).

Kuadran II : Infrastruktur yang butuh peningkatan perawatan (maintenance performance).

Kuadran III : Infrastruktur yang tidak mendesak untuk dikembangkan (medium-low priority).

Kuadran IV : Infrastruktur yang tidak perlu dikembangkan (possible over-kill).
Nilai kesenjangan antara tingkat kinerja dengan tingkat kepentingan dapat diketahui melalui tabel C-Line. Berikut merupakan tabulasi perhitungan C-Line pada SPSS.

Tabel 4.

Tabulasi $C$-Line

\begin{tabular}{lcc}
\hline \hline \multicolumn{1}{c}{ Jenis Infrastruktur } & $\begin{array}{c}\text { Tingkat } \\
\text { Kepentingan }\end{array}$ & $\begin{array}{c}\text { Tingkat } \\
\text { Kinerja }\end{array}$ \\
\hline Penyediaan Jaringan Jalan & 3.8 & 1.5 \\
Moda Transportasi & 3.5 & 1.5 \\
Penandaan atau Penunjuk Arah & 3.83 & 3.83 \\
Terminal Angkutan & 3.16 & 1.5 \\
Jaringan Listrik & 3.3 & 1 \\
Jaringan Air Bersih & 3.5 & 1.6 \\
Jaringan Telekomunikasi & 3.8 & 1 \\
Penyediaan Sampah Terpusat & 4 & 2.66 \\
TIC (tourism information centre) & 3.8 & 3.66 \\
Penyediaan Lahan Parkir Terpusat & 3.8 & 2.16 \\
Penyediaan kantor / pos keamanan & 3.3 & 3.33 \\
Penyediaan pos kesehatan & 3.8 & 1.33 \\
Penyediaan titik evakuasi & 4 & 1.33 \\
Penyediaan Toilet & 3.66 & 1 \\
Wisata Kuliner & 2.83 & 1 \\
Penyediaan fasilitas penginapan & 2 & 2 \\
Pusat oleh - oleh & 2.66 & 1 \\
Gazebo (shelter) & 3.16 & 3.16 \\
Tempat duduk keluarga / individu & 1.66 & 1.16 \\
\hline Jumlah & $\mathbf{6 3 , 8 0}$ & $\mathbf{3 5 , 8 3}$ \\
\hline C-Line & $\mathbf{3 , 3 5}$ & $\mathbf{1 , 8 7}$ \\
\hline & & \\
\hline & & \\
\hline & &
\end{tabular}

Dari hasil analisis C-Line, dapat disimpulkan bahwa kesenjangan paling tinggi terdapat pada variabel infrastruktur penyediaan jalur/titik evakuasi yang mempunyai nilai tingkat kepentingan yang tinggi (sebesar 4), tetapi memiliki tingkat kinerja yang sangat rendah (sebesar 1,33). Sedangkan variabel yang mempunyai kesenjangan rendah atau dikategorikan sudah memiliki kinerja yang cukup baik yaitu penandaan/petunjuk arah, dimana nilai tingkat kepentingan pada variabel ini sebesar 3,85 dan mempunyai tingkat kinerja yang serupa yaitu berada pada angka 3,85 . Berikut merupakan matriks IPA sebagai output SPSS yang membagi masingmasing infrastruktur ke dalam 4 kuadran.

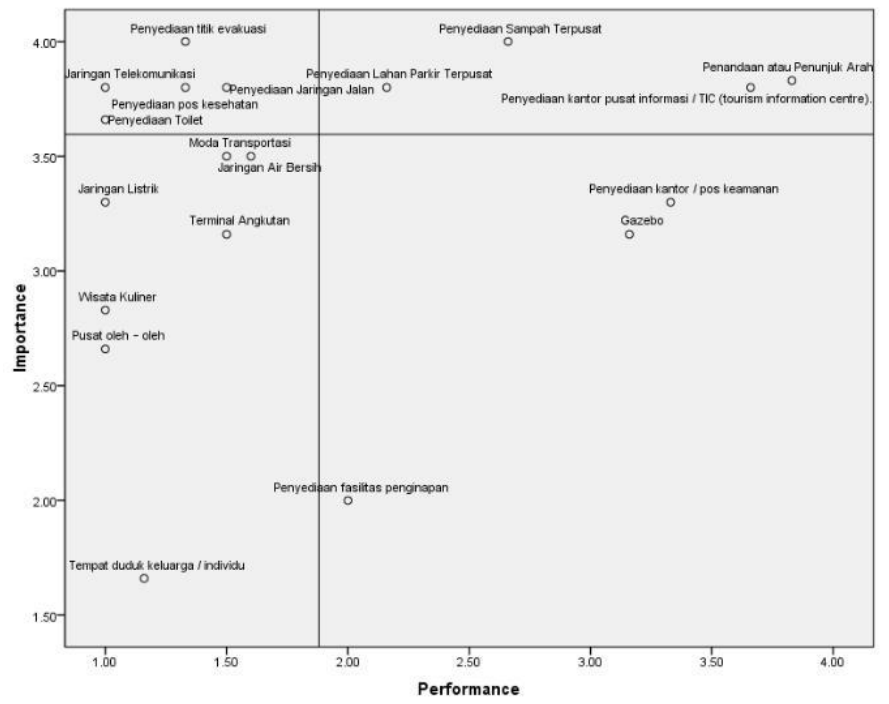

Gambar 7. Matriks IPA 
Berikut merupakan pembagian infrastruktur berdasarkan 4 kuadran prioritas.

- Kuadran I (focus effort here)

1. Penyediaan Titik Evakuasi

2. Penyediaan Jaringan Jalan

3. Penyediaan Pos Kesehatan

4. Penyediaan Toilet

5. Terminal Angkutan

6. Moda Transportasi

7. Jaringan Telekomunikasi

- Kuadran II (Maintance Performance)

1. Penandaan / Petunjuk Arah

2. Penyediaan Lahan Parkir

3. Penyediaan Kantor informasi

4. Penyediaan Sampah

- Kuadran III (Medium-Low Priority)

1. Wisata Kuliner

2. Jaringan Listrik

4. Tempat Duduk

5. Jaringan Air Bersih

- Kuadran IV (Possible over-kill)

1. Penyediaan Kantor Kamanan

2. Gazebo (shelter)

3. Penyediaan Penginapan

Jika diurutkan berdasarkan infrastruktur yang memiliki tingkat kinerja dan kepentingan tertinggi hingga tertendah, maka infrastruktur prioritas pada wisata pantai Teluk Hijau adalah sebagai berikut:

1. Jaringan Telekomunikasi

2. Penyediaan Toilet

3. Penyediaan Pos Kesehatan

4. Penyediaan Titik Evakuasi

5. Penyediaan Jaringan Jalan

6. Moda Transportasi

7. Terminal Angkutan

Diluar ketujuh infrastruktur tersebut, infrastruktur lain dikategorikan sebagai infrastruktur non prioritas, karena infrastruktur tidak dianggap penting oleh stakeholder dan mayoritas dilayani di luar wilayah Teluk Hijau.

\section{KESIMPULAN}

1) Berdasarkan tingkat kinerja infrastruktur eksisting, maka nilai tertinggi adalah penandaan (penunjuk arah),

2) Infrastruktur dengan tingkat kinerja terendah adalah jaringan listrik, jaringan telekomunikasi, penyediaan toilet, wisata kuliner, dan pusat oleh-oleh.

3) Berdasarkan persepsi stakeholder, maka infrastruktur dengan tingkat kepentingan tertinggi adalah penyediaan titik evakuasi.

4) Terdapat 7 green infrastruktur prioritas pada wisata pantai Teluk Hijau, yaitu jaringan telekomunikasi, penyediaan pos kesehatan, penyediaan titik evakuasi, penyediaan jaringan jalan, penyediaan toilet, moda transportasi dan terminal angkutan.

\section{REKOMENDASI}

Adapun rekomendasi yang dapat diberikan berdasarkan hasil penelitian ini adalah sebagai berikut :

1) Dapat dijadikan landasan atau acuan oleh pemerintah daerah dalam melakukan pengembangan green infrastruktur wisata pantai Teluk Hijau untuk mendukung dalam kenyamanan wisatawan.

2) Terkait pemenuhan kebutuhan green infrastruktur maka diperlukan adanya kerjasama antara pemerintah daerah Kabupaten Banyuwangi khususnya pada Kecamatan Pesanggaran ,Desa Sarongan, dan Kelompok Sadar Wisata.

3) Diperlukan adanya studi lanjutan mengenai perhitungan daya dukung dan daya tampung mengenai wisata pantai Teluk Hijau.

\section{DAFTAR PUSTAKA}

[1] Haryono Wing, 1978. Pariwisata, Reakreasi dan Entertainmen. Bandung : Ilmu Publisher.

[2] Undang - undang No 9 Tahun 1990 Tentang Kepariwistaan Nasional.

[3] Lea, J. 1988. Tourism and Development in the Third World. London : Routledge

[4] Hesna, Yervi. 2016. Kajian Kapasitas Infrastruktur : Suatu Upaya Peningkatan Pariwisata Sumatera Barat. Teknik Sipil Univeristas Andalas

[5] Razak, Abdur. (2013), Pengembangan Kawasan Pariwisata Terpadu di Kepulauan Seribu. Surabaya: Institut Teknologi Sepuluh Nopember.

[6] Faria, Novida. (2011), Obyek Wisata Pantai TirtoSamudra berpotensi Meningkatkan Kehidupan Sosial Ekonomi Masyarakat. Institut Teknologi Sepuluh Nopember.

[7] Peraturan Daerah Kabupaten Banyuwangi Nomor 08 Tahun 2012 tentang Rencana Tata Ruang Wilayah Kabupaten Banyuwangi Tahun 2012-2032.

[8] Rencana Strategis (Renstra) Dinas Kebudayaan dan Pariwisata 2016. Prioritas Pembangunan Infrastruktur Pariwisata Kabupaten Banyuwangi.

[9] Gunena, Nofrison. 2013. Peran Lurah Dalam Pembangunan Infrastruktur di Kelurahan Kolongan Kecamatan Tahun Barat Kabupaten Sangihe.

[10] Siregar, Lastriana. 2011. Faktor-Faktor Utama Yang Mempengaruhi Wisatawan Asing Terhadap Pemilihan Daerah Tujuan Wisata di Bali. Bogor : Institut Pertanian Bogor.

[11] Hidayat, Nur. 2016. Arahan Pengembangan Infrastruktur Wilayah Pesisir Kecamatan Pasean Kabupaten Pamekasan. Surabaya: Institut Teknologi Sepuluh Nopember.

[12] Arafah, Willy. 2015. Pembangunan Berkelanjutan (Sustainable Development) Pada Sektor Pariwisata di Propinsi Bengkulu. Jakarta : Universitas Trisakti. 